\title{
Aboriginal Bacterial Flora in the Uricase-Deficient Rat Gut is Not the Main Factor Affecting Serum Uric Acid
}

\author{
Nan Fan $\left(\mathbb{D},{ }^{1}\right.$ Lvyu Li, ${ }^{2,3}$ Heng Xia ${ }^{10},{ }^{2}$ Yinfang Gao, ${ }^{1}$ Yongkun Li, ${ }^{2}$ Huan Chen $\mathbb{D}^{2}{ }^{2}$ \\ Yu Yun iD, 1 and Weigang Duan iD ${ }^{2}$ \\ ${ }^{1}$ The Department of Pharmacology, School of Basic Medicine, Kunming Medical University, Kunming 650500, Yunnan, China \\ ${ }^{2}$ Yunnan Provincial Key Laboratory of Molecular Biology for Sinomedicine, School of Basic Medicine, \\ Yunnan University of Traditional Chinese Medicine, Kunming 650500, Yunnan, China \\ ${ }^{3}$ The Third Affiliated Hospital, Yunnan University of Traditional Chinese Medicine, 25, Eastern Dongfeng Rd., Kunming 650051, \\ Yunnan, China \\ Correspondence should be addressed to Weigang Duan; deardwg@126.com
}

Received 1 March 2021; Revised 22 April 2021; Accepted 7 May 2021; Published 19 May 2021

Academic Editor: Chan-Yen Kuo

Copyright $\odot 2021$ Nan Fan et al. This is an open access article distributed under the Creative Commons Attribution License, which permits unrestricted use, distribution, and reproduction in any medium, provided the original work is properly cited.

\begin{abstract}
The relationship between intestinal bacteria and hyperuricemia is a hot research topic. To better understand this relationship, uricase-deficient Sprague-Dawley rats (Kunming-DY rats) were used. The wild-type rats and Kunming-DY rats were used as controls. Kunming-DY rats were treated with ampicillin $(90 \mathrm{mg} / \mathrm{kg})$ and ciprofloxacin $(150 \mathrm{mg} / \mathrm{kg})$ for 5 days. Bacterial $16 S$ rDNA in the fresh stool was sequenced, and the abundance was calculated. The rats' serum uric acid (SUA) level was assayed, and the rats' intake and output in $24 \mathrm{~h}$ were recorded. The bacterial diversity in three groups' fresh stool was analyzed. The gut bacterial diversity and abundance changed in the Kunming-DY rats. More than $99 \%$ of bacteria were inhibited or killed by the combination of antibiotics. In contrast to each of the antibiotics alone, the combination of antibiotics lowered the Kunming-DY rats' SUA level; it also caused mild diarrhea, which increased uric acid excretion through stool. These results suggested that the aboriginal gut bacteria in uricase-deficient rats play a minor role in determining the SUA levels. It is too early to conclude that aboriginal gut bacteria are a tempting target for lowering SUA levels.
\end{abstract}

\section{Introduction}

Hyperuricemia and associated disorders are a common threat to human health in modern society. Approaches to effectively controlling these disorders are a hot topic in medical science fields. The critical solution is to keep the serum uric acid (SUA) level below $70 \mu \mathrm{g} / \mathrm{ml}$ [1]. Such a strategy has been supported by the results of epidemiologic studies at a large scale, considering that the lower SUA levels are highly correlated with less frequent attacks of gout or related diseases [1].

Uric acid is synthesized by xanthine dehydrogenase (Xdh) and can be degraded by uricase (urate oxidase, Uox). Therefore, in humans and animals that do not express uricase, uric acid is an end product of purine metabolism, namely, in humans, a gene encoding uricase is a pseudogene that can be transcribed without translation. The strategies for lowering SUA levels can be grouped into two classes; one strategy is to inhibit uric acid synthesis and the other is to increase uric acid excretion through urine or the intestinal tract. The intestinal tract is a new effective target to lower the SUA level because the amount of uric acid distributed in intestinal fluids is about two or three times higher than that in blood [2]. The effectiveness of targeting the intestinal tract to lower the SUA level has been shown after treatment with oral uricase $[2,3]$, oral urate sorbents, such as montmorillonite [4], and laxatives [5].

The intestinal tract is a dominant place where microbes reside. Since uricase is almost universally expressed in microorganisms [6], it is taken for granted that microbes play a vital role in lowering the SUA levels. The SUA levels can be lowered by altering gut microbiota [7] or inoculating 
engineered bacteria that highly express uricase [8]. However, microorganisms are highly metabolically active in the gut; they also synthesize purines, the substrates for uric acid, and express uricase to degrade uric acid. Furthermore, most experiments on lowering the SUA levels by affecting bacteria were carried out in animals who expressed uricase $[2-4,7,8]$. In order to exclude the tangling factor of the host's uricase, uricase-deficient $\left(\mathrm{Uox}^{-/-}\right)$rats were generated by our team on the background of Sprague-Dawley (SD) rats; they were named "Kunming-DY rats" [9], a type of closed colony animals rather than inbred animals, such as C57BL/6J $[10,11]$. Different from $\operatorname{Uox}^{-/-}$mice $[10,11]$, the SUA level in the male $\mathrm{Uox}^{-/-}$rats was about $48.3 \pm 19.1 \mu \mathrm{g} / \mathrm{ml}$ [9], which significantly increased but still much lower than that in $\mathrm{Uox}^{-/-}$mice. Since the level of SUA in the $\mathrm{Uox}^{-/-}$rats was similar to that in men, it has been suggested that the rats could be one of the optimal animals to study gout and associated diseases.

The present study investigated the aboriginal bacteria in the gut of $\mathrm{Uox}^{-/-}$rats and evaluated their relationship with SUA levels.

\section{Materials and Methods}

2.1. Materials. Wild-type SD rats of 45 days old were obtained from Chengdu Dossy Experimental Animals Co., Ltd., Chengdu, China (certification no. SCXK (Chuan) 2008-24). Uox ${ }^{-1-}$ (Kunming-DY) and wild-type rats of the same age (45 days old) were generated in our laboratory as previously described [9].

Uric acid assay kits of the phosphotungstic acid method (lot: C012-1-1) were purchased from Nanjing Jiancheng Bioengineering Institute (Nanjing, China). The Mag-MK Soil and Stool Genome DNA Extraction Kit (B618763) was purchased from Sangon Biotech (Shanghai) Co., Ltd. (Shanghai, China).

The fluorescent quantitative PCR apparatus (StepOne Plus) was manufactured by ABI (Foster, CA, USA). Ultrapure water was produced by a Milli $Q$ water purification system manufactured by EMD Millipore Group (Darmstadt, Germany). The NanoDrop ND-1000 spectrophotometer used for experiments was manufactured by PeqLab (Erlangen, Germany). The multiple microplate reader Infinite 200pro (Tecan Group, Mannedorf, Switzerland) was also used. Other instruments or reagents used in the present study were made in China.

2.2. Animal Breeding. Uox ${ }^{-/-}$rats were generated, identified, and raised in our laboratory as previously described [9]. Briefly, the male $\mathrm{Uox}^{-/-}$rats were mated with the female $\mathrm{Uox}^{-/-}$rats for three weeks to generate their offspring. Their offspring were breastfed by their mothers to the age of three weeks; then, the mothers, the male offspring, and the female offspring were separated and put in three individual cages. When the male offspring reached 45 days old, they were used in this study.

Five nests of male $\mathrm{Uox}^{-/-}$rats and two nests of male wildtype rats were enriched. The rats were kept at $22^{\circ} \mathrm{C}$, humidity of $45 \%-55 \%$, under natural light, and with an accessible approach to food and water. All animal experiments were approved by the Animal Care and Use Committee of Kunming Medical University (approval no. KMMU2020196) and performed under the Guidelines for Ethical Review of Laboratory Animal Welfare of China.

After the experiment, the living rats were intraperitoneally anesthetized with urethane $(1.0 \mathrm{~g} / \mathrm{kg})$. Under deep anesthesia, their necks were dislocated for euthanasia. The rat bodies had been collected in yellow plastic bags and kept in a refrigerator at $-20^{\circ} \mathrm{C}$ until they were taken away by a green company for cremation.

2.3. SUA Levels in Uox ${ }^{-/-}$Rats Treated with Ampicillin or Ciprofloxacin. Eighteen $\mathrm{Uox}^{-/-}$rats were randomized into three groups: ampicillin group (Am), ciprofloxacin group (Cip), and combination group (Am + Cip). Every group included six rats. The rats in the Am group were intragastrically administered with ampicillin $(90 \mathrm{mg} / \mathrm{kg})$ for 5 days, the Cip group was treated with ciprofloxacin $(150 \mathrm{mg} /$ $\mathrm{kg}$ ), and the Am + Cip group was treated with ampicillin $(90 \mathrm{mg} / \mathrm{kg})$ in the morning and ciprofloxacin $(150 \mathrm{mg} / \mathrm{kg})$ in the afternoon. Twelve $\mathrm{Uox}^{-/-}$rats were randomized into the control group and treated with normal saline of the same volume $(10 \mathrm{ml} / \mathrm{kg})$.

Before they were administered with drugs, the rats had been kept in metabolic cages to obtain their intake of food and water and output of urine and stool in $24 \mathrm{~h}$. In addition, a $200-\mu$ l blood sample without anticoagulation was drawn from their tail vein using a tiny needle. During blood sampling, the animals were awake at a local atmosphere of $28^{\circ} \mathrm{C}-32^{\circ} \mathrm{C}$. Serum was obtained by spinning at $3,000 \mathrm{~g}$ and $4^{\circ} \mathrm{C}$ for $5 \mathrm{~min}$ as soon as the blood coagulated. At the end of the five-day experimental period, the animals were individually kept in metabolic cages. We recorded the amount of food and water they consumed in the last $24 \mathrm{~h}$. Their stool and excreted urine were also collected and recorded; they were collected on ice in a cold insulation box for analysis.

The urine was soon stirred to a homogeneous state, and $1.2 \mathrm{ml}$ was sampled. The urine sample was quickly diluted 20 times to obtain the final sample for a uric acid assay. The stool was weighed and then mixed with 3 -fold weight of Tris solution $(100 \mathrm{mmol} / \mathrm{L})$, and the mixture was stirred at a shaker at $100 \mathrm{rpm}$ for $4 \mathrm{~h}$. The mixture was spun at 5,000 $\mathrm{g}$ and $4^{\circ} \mathrm{C}$ for $5 \mathrm{~min}$, and the supernatant was collected for the final uric acid assay.

The samples for uric acid assay were kept at $-20^{\circ} \mathrm{C}$ or determined as soon as possible to prevent the false elevation of uric acid levels by xanthine dehydrogenase in rat samples [12]. Uric acid in the final samples was assayed using the uric acid assay kits. The assay kits had a quantification range of uric acid from $3.91 \mu \mathrm{g} / \mathrm{ml}$ to $125 \mu \mathrm{g} / \mathrm{ml}$. If the uric acid levels in the samples had exceeded the kits' quantification range, the samples were diluted. The protocol of uric acid assay kit is available at the following website: http://www.njjcbio.com/uploadfile/product/big/ 20190612093216738.pdf. 
2.4. Fresh Stool Prepared from Rats. Twelve Uox ${ }^{-/-}$rats were randomized into the normal $\mathrm{Uox}^{-{ }^{-}}$group $\left(\mathrm{Uox}^{-/-}-1\right)$ and the combination group (Uox $\left.{ }^{-/-}-2\right)$. Each group contained six rats, as mentioned above. Another six wild-type SD rats were randomized into the WT group. The rats in the $\mathrm{Uox}^{-1-}-2$ group were intragastrically given ampicillin $(90 \mathrm{mg} / \mathrm{kg})$ in the morning and ciprofloxacin $(150 \mathrm{mg} / \mathrm{kg})$ in the afternoon for 5 days. The rats in $\mathrm{Uox}^{-1-}-1$ or the WT group were treated with normal saline of the same volume $(10 \mathrm{ml} / \mathrm{kg})$. After the rats had been administered for 5 days, their fresh stool was collected. The stool was divided into two aliquots: one was used for microculture and the other for microbiome assay.

2.5. Microculture of Fresh Stool. Their stool was diluted with sterilized normal saline solution to $1: 10^{7}$. The mixture was adequately stirred, and $100 \mu \mathrm{l}$ was piped to the LB solid medium surface (containing $10 \mathrm{~g}$ peptone, $5 \mathrm{~g}$ yeast extract, $10 \mathrm{~g}$ sodium chloride, and $8 \mathrm{~g}$ agar-agar in $1,000 \mathrm{ml}$ and autoclaved) in a culture dish of 30 square inches. The mixture was evenly dispersed to cover the surface of the dish. The culture dishes were kept at $37^{\circ} \mathrm{C}$ for $24 \mathrm{~h}$. The dishes were photographed, and the clones on the surface of the solid medium were counted.

2.6. Microbiome Assay of Fresh Stool. The other aliquot of the fresh stool, about $200 \mathrm{mg}$, was used to extract DNA using the Mag-MK Soil and Stool Genome DNA Extraction Kit. The DNA quality and quantity were measured by the NanoDrop ND-1000 spectrophotometer.

The DNA encoding bacterial 16S rRNA was amplified by 25 cycles with primers Bakt_341F (CCTACGGGNGGCWGCAG) and Bakt_805R (GACTACHVGGGTATCTAATCC) [13]. The $5^{\prime}$ end of the primers was designed as adapters for purification, which were CCCTACACGACGCTCTTCCGATCTG and GACTGGAGTTCCTTGGCACCCGAGAATTCCAy [13]. The purified 16S rDNA (about 466bp) was assessed by a standard agarose gel electrophoresis and was sequenced by Sangon Biotech (Shanghai, China). The quality and quantity of the amplified DNA were also measured by the NanoDrop ND-1000 spectrophotometer. The amplified sequences were purified and sequenced on the Illumina MiSeq platform (Sangon Biotech). The sequence of the reads were BLASTed with gene banks (http://rdp.cme.msu.edu/misc/resources.jsp, http:// www.arb-silva.de/, and http://ncbi.nlm.nih.gov/), and the positive sequences (species annotation) were recognized by $\geq 97 \%$ sequence similarity. The reads were clustered into operational taxonomic units (OTUs) by referring to the $16 \mathrm{~S}$ rDNA database. The flora's alpha diversity in every group was measured using the Shannon index (https://mothur.org/ wiki/shannon/). Principal component analysis (PCA) was performed to evaluate their beta-diversity.

The exact copies of rDNA in the $50 \mathrm{mg}$ stool sample were also assayed using the quantitative PCR method by the fluorescent quantitative PCR apparatus. Briefly, the rDNA in the samples was extracted, diluted to 50 or 10 -fold, and amplified with the primers mentioned above. The anticipated PCR products were about $466 \mathrm{bp}$. The reaction solution of $20 \mu \mathrm{l}$ contained SybrGreen qPCR Master Mix $(10 \mu \mathrm{l})$, primers $(10 \mu \mathrm{M}, 0.4+0.4 \mu \mathrm{l})$, ultrapurified water $(7.2 \mu \mathrm{l})$, and templates $(2 \mu \mathrm{l})$. PCR was carried out with predenaturation at $95^{\circ} \mathrm{C}$ for $3 \mathrm{~min}$, followed by 45 cycles of denaturation step at $95^{\circ} \mathrm{C}$ for $5 \mathrm{~s}$, annealing at $60^{\circ} \mathrm{C}$ for $30 \mathrm{~s}$, and extension at $72^{\circ} \mathrm{C}$ for $30 \mathrm{~s}$. Finally, an additional extension at $72^{\circ} \mathrm{C}$ for $8 \mathrm{~min}$ was performed, and the melting curve of the product was determined. The green fluorescence at every cycle of the reaction was recorded, and the quality of the PCR product was evaluated by the melting curve. The cycle threshold value (CT), indicating the templates' relative abundance, was calculated by the amplification curve. By comparison with the standard amplified PCR products, the exact copies in every rDNA sample were calculated.

2.7. Statistical Analyses. Values were expressed as mean+ standard deviation (SD) or mean + standard error (SE). If a normal distribution of the original values (or logarithmically transformed) was verified by the normality test (Shapiro-Wilk test), Student's $t$-test or one-way analysis of variance (ANOVA) was performed to compare the means between different groups. If there was a significant difference in ANOVA, the post hoc statistical tests between each two groups were performed with the S-N-K method (equal variances assumed) or with Tamhane's T2 method (equal variances not assumed). Otherwise, a nonparametric test for two independent samples in the Mann-Whitney $U$ model (two-tailed) was performed. The correlation between the Uox $^{-/-}$rat SUA levels and other factors was tested using Pearson's correlation (two-tailed). Statistical significance was accepted at $P<0.05$.

\section{Results}

3.1. SUA Levels in Uox ${ }^{-1-}$ Rats Treated with Antibiotics. The SUA levels in $\mathrm{Uox}^{-/-}$rats were relatively stable during 5 days (Figure 1(a)). However, when the rats were treated with the combination of antibiotics (ampicillin, $90 \mathrm{mg} / \mathrm{kg}$, and ciprofloxacin, $150 \mathrm{mg} / \mathrm{kg}$ ), the SUA levels decreased rather than increased (Figure 1(b)). Ampicillin $(90 \mathrm{mg} / \mathrm{kg}$ ) had almost no significant effects on the rat SUA levels (Figure 1(c)). To our surprise, ciprofloxacin $1(50 \mathrm{mg} / \mathrm{kg})$ increased the rat SUA level (Figure 1(d)).

3.2. Intake and Output of Uox ${ }^{-/-}$Rats Treated with Ampicillin and Ciprofloxacin. Uox $^{-1-}$ rats consumed the same quantity of food (Figure 2(a)) after treatment with the combination of antibiotics. The consumed water increased after the rats had been treated with the antibiotics, but without reaching significance (Figure 2(b)). Simultaneously, the rats excreted urine of the same volume (Figure 2(c)), but they excreted more stool (Figure 2(d)). Since there was no difference and tendency in food consumed between day 0 and day 5 , there was an increasing tendency in water intake and the increased stool contained more water, suggesting that the rats had mild diarrhea. 


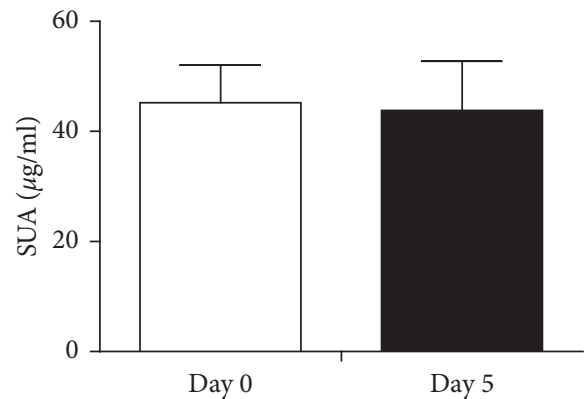

(a)

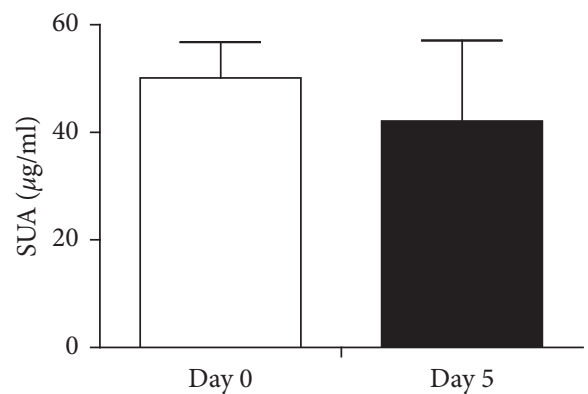

(c)

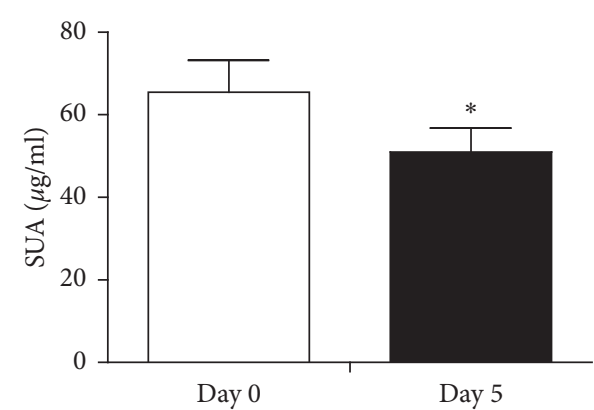

(b)

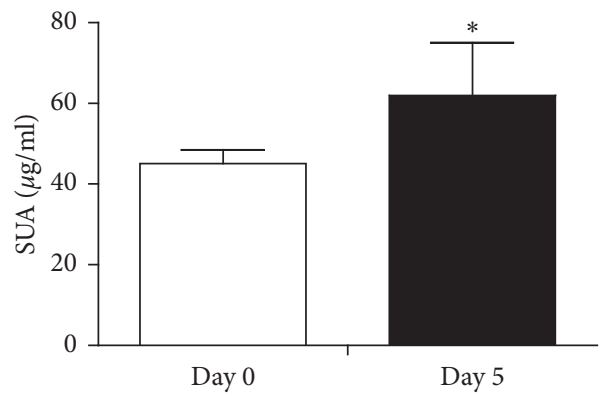

(d)

Figure 1: Serum uric acid (SUA) levels in male $\mathrm{Uox}^{-/-}$rats treated with antibiotics (mean $+\mathrm{SD}, n=12$ (control) or 6 (antibiotics)). (a) control group, treated with normal saline; (b) Am + Cip group, treated with ampicillin (90 mg/kg) and ciprofloxacin (150 mg/kg); (c) Am group, treated with ampicillin $(90 \mathrm{mg} / \mathrm{kg})$; (d) Cip group, treated with ciprofloxacin $(150 \mathrm{mg} / \mathrm{kg})$. Day 0 , the day before treatment; day 5 , treated with drugs for 5 days. ${ }^{*} P<0.05$ vs. day 0 , paired-sample $t$-test.

\subsection{Uric Acid in Uox ${ }^{-/-}$Rat Urine and Stool Treated with} Antibiotics. Since the SUA level in $\mathrm{Uox}^{-/-}$rats was lowered by the combination of antibiotics, it should be explained whether this was associated with the increase in uric acid excretion. Unsurprisingly, there was a tendency toward increased uric acid in urine at concentration (Figure 3(a)) and amount (Figure 3(c)) levels, although neither of the levels reached statistical significance. However, the uric acid excreted through stool significantly increased at both concentration (Figure 3(b)) and amount (Figure 3(d)) levels. The increased uric acid in urine and stool could be the logical cause of the lowered SUA level (Figure 1(b)).

\subsection{Bacterial Abundance in Uox ${ }^{-/-}$Rat Stool Measured by} Culturing. The fresh stool was diluted to $10^{7}$ folds and cultured on the surface of the solid LB medium. Aerobic bacteria grew on the surface and developed clones. The data of clones in the three groups were logarithmically transformed before statistical analysis. Figure 4 showed that there were more bacteria in Uox $^{-/-}$rat stool (Figures 4(b) and 4(d)) than in that of wild-type rats (Figures 4(a) and 4(d)), although the difference did not reach significance. Bacteria in $\mathrm{Uox}^{-/-}$rat stool significantly decreased if their hosts were treated with the combination of antibiotics for 5 days (Figures 4(c) and 4(d)). The number of aerobic bacteria in the stool of $\mathrm{Uox}^{-/-}$rats treated with the combination of antibiotics was about $0.43 \%$ of that in normal Uox $^{-/-}$rat stool, suggesting that the bacteria were dramatically killed or inhibited by the combination of antibiotics.
3.5. Bacterial Abundance in Uox ${ }^{-/-}$Rat Stool Measured by DNA. Bacteria contain DNA. More DNA was extracted from $\mathrm{Uox}^{-/-}$rat stool than from wild-type rat stool of the same weight (Figures 5(a) and 5(b)). However, less DNA was extracted from the stool of the $\mathrm{Uox}^{-/-}$rats treated with the combination of antibiotics for 5 days (Figures 5(a) and 5(b)). There was a good positive correlation between the amount of bacterial DNA and the quantity of living bacteria (Figure 5(c)), suggesting that the amount of bacterial DNA can be a macroscopic evaluation index in evaluating the relative abundance of bacteria.

The sample containing $16 \mathrm{~S}$ rDNA was amplified in a quantitative model by the fluorescent quantitative PCR apparatus. The CT value was obtained from the amplification curve. The CT value of the sample containing 16S rDNA from $\mathrm{Uox}^{-/-}$rat stool was lower than that of wild-type rats, while the CT value from stool of $\mathrm{Uox}^{-/-}$rats treated with the combination of antibiotics was the highest (Figure 5(d)). Further results showed that $\mathrm{Uox}^{-/-}$rat stool had the highest number of copies of $16 \mathrm{~S}$ rDNA, and stool from $\mathrm{Uox}^{-/-}$rats treated with the combination of antibiotics had the lowest (Figure 5(e)), about $1.03 \%$ of that in stool of normal $\mathrm{Uox}^{-/-}$rats. Because the exact copies were calculated from the CT values, a low CT value also meant a high abundance of $16 \mathrm{~S}$ rDNA. There was a strong negative correlation between the CT values and the number of living bacteria (Figure 5(f)), suggesting that the CT value can be used to evaluate the relative abundance of bacteria.

3.6. Bacterial Flora in Uox $x^{-/-}$Rat Stool. The stool rDNA was amplified, sequenced, and BLASTed. Finally, 937 OTUs were obtained in all the samples, more than $99.9 \%$ of which 


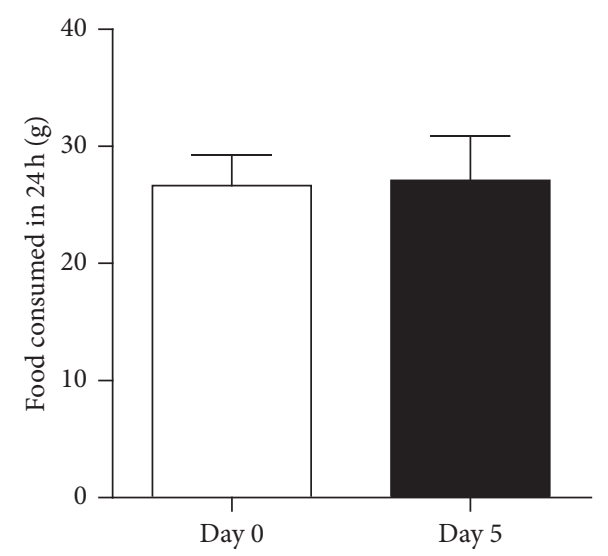

(a)

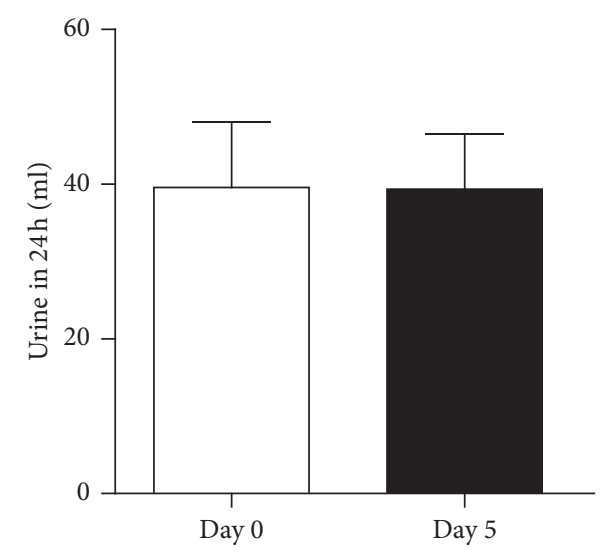

(c)

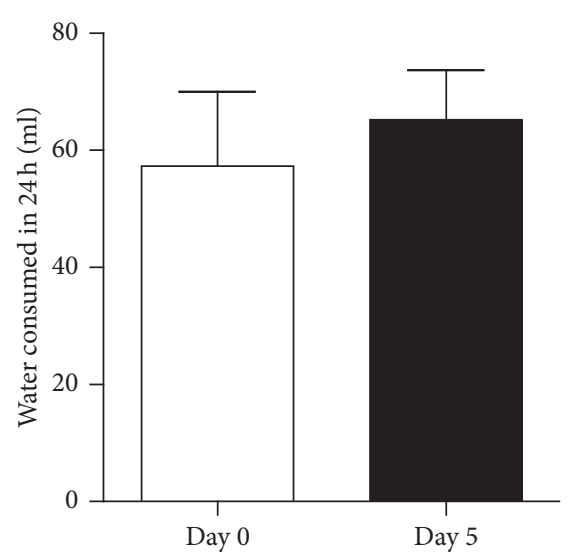

(b)

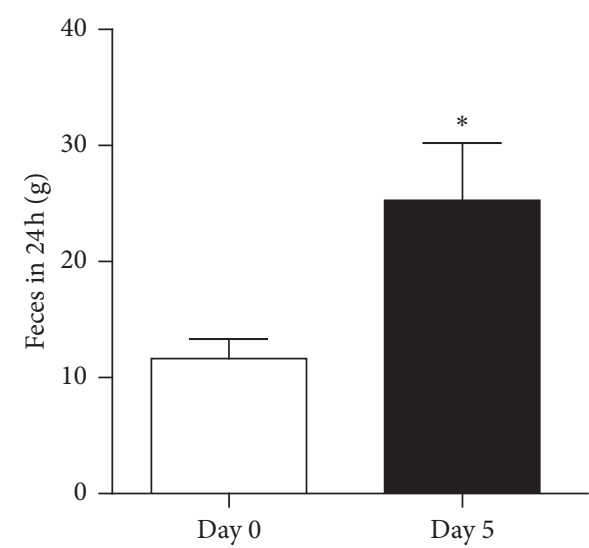

(d)

Figure 2: Food and water intake and urine and stool output of the male Uox ${ }^{-1-}$ rats treated with antibiotics for 5 days $(\mathrm{mean}+\mathrm{SD}, n=6$ ). There were no significant differences between day 0 and day 5 in food (a) and water (b) consumption in $24 \mathrm{~h}$. There was no difference between day 0 and day 5 in the volume of $24 \mathrm{~h}$ urine (c) either. However, in day 5 , the rats excreted more amount of stool (d). Day 0 , the day before treatment; day 5 , treated with ampicillin $(90 \mathrm{mg} / \mathrm{kg})$ and ciprofloxacin $(150 \mathrm{mg} / \mathrm{kg})$ for 5 days. ${ }^{*} P<0.05$ vs. day 0 , paired-sample $t$-test.

clustered in the bacteria domain. Further annotation results showed that they were clustered in 33 phyla, 41 classes, 83 orders, 157 families, 348 genera, and 461 species. The results of the alpha diversity analysis, as shown in Figure 6(a), elucidated that the $\mathrm{Uox}^{-1-}$ rat stool had more species measured by OTUs. The results suggested that uricase-deficiency increased the bacterial diversity, and the combination of antibiotics significantly decreased the bacterial diversity.

Beta-diversity was determined based on the PCA, and the results are shown at OTU (Figure 6(b)), genus (Figure 6(c)), and species (Figure 6(d)) levels. The results clarified that the bacterial pattern was significantly differed between the groups. However, according to the results shown in Venn distribution of the bacteria in $\mathrm{Uox}^{-1-}$ rat stool at OTU (Figure 7(a)) and genus (Figure 7(b)) levels, about $60 \%$ of the bacteria were still shared among the three groups, at both the OTU level and genus level.

3.7. Bacterial Abundance in Uox ${ }^{-/-}$Rat Stool. Since the bacterial abundance in stool of $\mathrm{Uox}^{-/-}$rats treated with antibiotics for 5 days dramatically decreased (Figures 4 and
5), about $1 \%$ even less than those in the normal $\mathrm{Uox}^{-/-}$rat stool, their bacterial abundance was listed without being analyzed with other two groups. The top 10 bacteria in the wild-type rat stool were listed at phylum (Figure 8(a)), class (Figure 8(b)), order (Figure 8(c)), family (Figure 8(d)), genus (Figure 8(e)), and species (Figure 8(f)) levels, and those in $\mathrm{Uox}^{-/-}$rats were compared at the same levels in the same thumbnails (Figures $8(a)-8(f)$ ). Most of the main bacteria in $\mathrm{Uox}^{-/-}$rat stool were significantly different from those in the wild-type rats.

The top 10 bacteria in the three groups' stool were listed at the genus (Table 1) and species (Table 2) levels. Since the top 10 bacteria accounted for more than $50 \%$ of abundance, bacteria could be an important factor maintaining the microecological balance in the intestinal tract.

\section{Discussion}

Bacteria are an essential part of microecology in the gut. They are also regarded as a concerned factor affecting multiple aspects of health, including diabetes mellitus, hypertension, and hyperlipidemia [14]. Bacteria might 


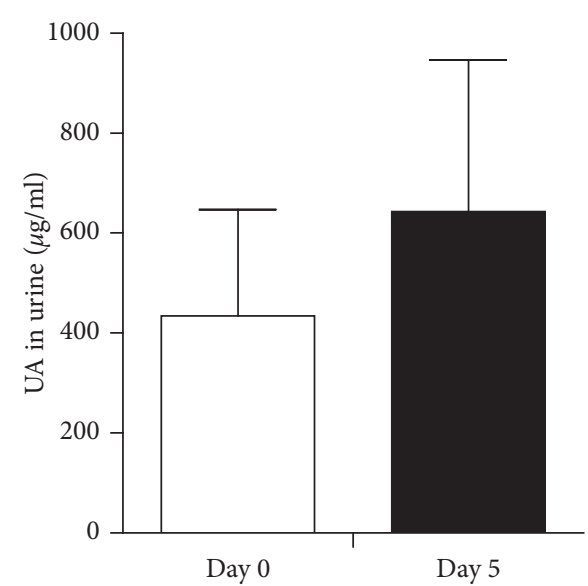

(a)

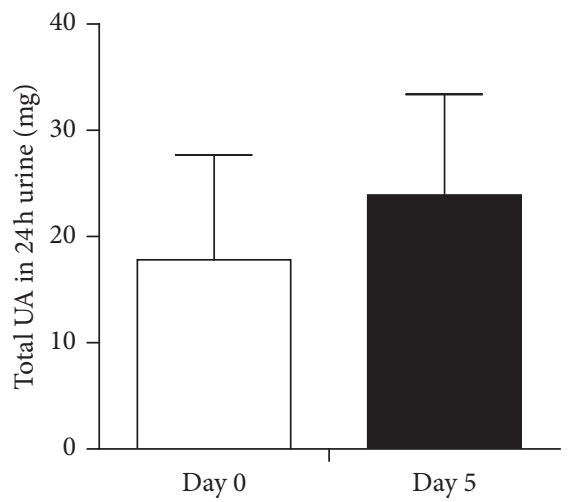

(c)

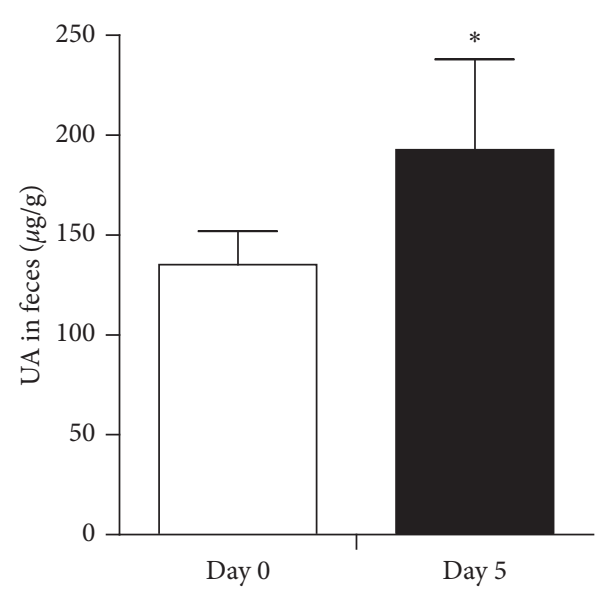

(b)

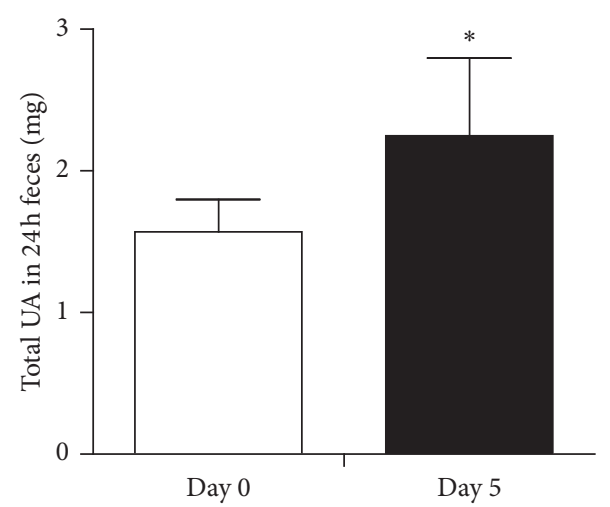

(d)

FIgURe 3: Uric acid in urine and stool excreted by the male Uox ${ }^{-/-}$rats treated with antibiotics for 5 days $($ mean + SD, $n=6)$. When treated with the combination of antibiotics for 5 days, the rats excreted more uric acid in their urine (a, c), but without reaching statistical significance; however, they significantly excreted more uric acid in stool at both concentration (b) and amount (d) levels in $24 \mathrm{~h}$. Day 0 , the day before treatment; day 5 , treated with ampicillin $(90 \mathrm{mg} / \mathrm{kg})$ and ciprofloxacin $(150 \mathrm{mg} / \mathrm{kg}) .{ }^{*} P<0.05$ vs. day 0 , paired-samples $t$-test.

contribute to hyperuricemia because it has been shown that inoculated engineered bacteria lowered SUA levels [8]. However, most experimental animals with hyperuricemia were established by administered oral uricase inhibitor or high purine diet. The administration could be an additional factor disturbing the aboriginal bacterial flora. The Uox ${ }^{-1-}$ rats naturally develop high SUA levels. The animals could be one of the optimal choices to study the relationship between the SUA level and the aboriginal gut microbiome. The gut microbiome in $\mathrm{Uox}^{-/-}$rodents has not been explored before, and the bacterial flora in the $\operatorname{Uox}^{-/-}$rats was first investigated in this study.

\subsection{Uricase-Deficiency Alters the Bacterial Flora in Rats.} The abundance of bacteria in $\mathrm{Uox}^{-/-}$rat stool was higher than that in the wild-type rats, and the alpha-bacterial diversity increased. The pattern of bacterial flora in the $\mathrm{Uox}^{-/-}$rats was significantly different from that in the wild-type rats. However, the bacterial pattern was further altered if the combination of antibiotics was administered for 5 days. Since the bacteria in fresh stool originated in their host's intestinal tract, the different bacterial patterns in stool largely reflected the bacteria residing in the host's intestinal tract. The difference in bacteria between the stool of $\mathrm{Uox}^{-/-}$rats and that of wild-type rats could originally result from uricase-deficiency and directly from the increase of uric acid in the intestinal tract. Namely, the uricase-deficiency caused the high level of uric acid in the Uox ${ }^{-/-}$rat gut and then affected the bacteria survival and growth. For instance, uric acid is a possible "food" for some bacteria; hence, uric acid would facilitate their survival and growth. The bacteria in the $\mathrm{Uox}^{-/-}$rat gut could be more likely "uratophilic" bacteria, but they need further research. Several genera in the top 10 bacteria (Table 1) of the $\mathrm{Uox}^{-/-}$rat stool were shown to generate uricase (Table 3), which would facilitate their utilization of uric acid. It should be noted that other bacteria could also generate uricase though needed verification.

\subsection{Aboriginal Bacteria in Uox ${ }^{-/-}$Rat Gut Are Not the Main} Factor Affecting SUA Levels. High uric acid distributed in the rat intestinal tract was proved to be an important way to lower the SUA level by oral uricase and laxatives $[2,3]$. The aboriginal bacteria in the $\mathrm{Uox}^{-/-}$rat intestinal tract can be killed or inhibited by antibiotics such as ampicillin and 


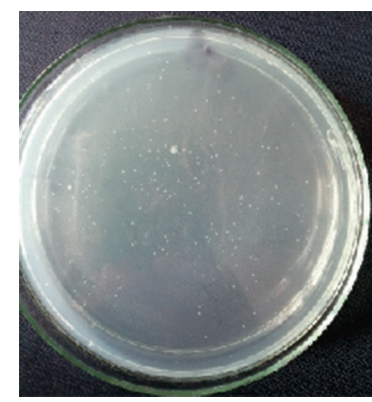

(a)

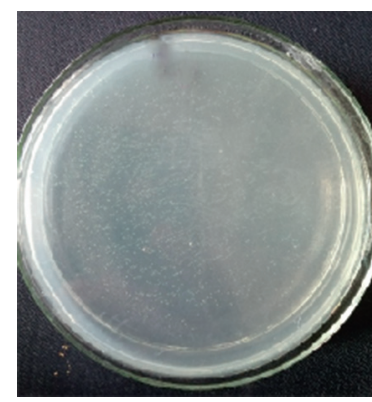

(b)

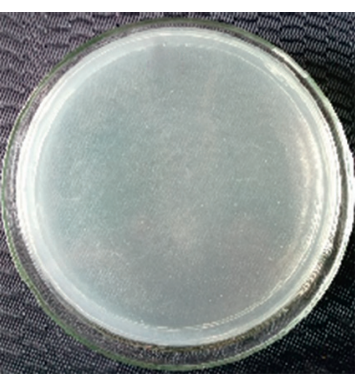

(c)

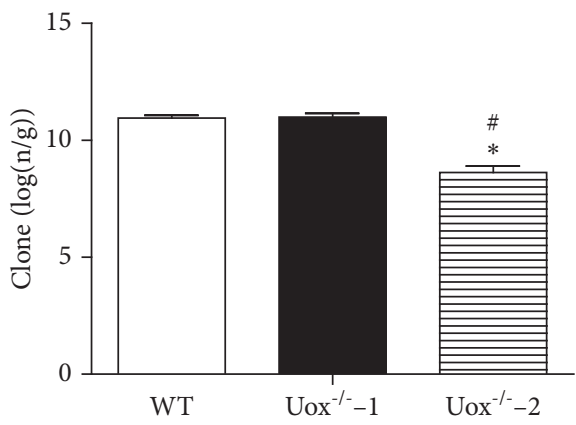

(d)

Figure 4: Bacterial abundance in the Uox $^{-1-}$ rats measured by culturing clones on the solid LB medium. The fresh stool was diluted to $10^{7}$ folds, and a $100 \mu \mathrm{l}$ sample was cultured on the surface. The aerobic bacteria grew on the surface and developed clones. The data of clones in the three groups were logarithmically transformed before statistical analysis. (a) Clones from the wild-type rat stool, (b) clones from the $\mathrm{Uox}^{-/-}$rat stool, (c) clones from the stool of $\mathrm{Uox}^{-/-}$rat treated with ampicillin $(90 \mathrm{mg} / \mathrm{kg}$ ) and ciprofloxacin $(150 \mathrm{mg} / \mathrm{kg})$ for $5 \mathrm{days}$, (d)

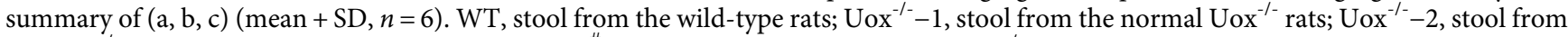
the $\mathrm{Uox}^{-/-}$rats treated with antibiotics for 5 days. ${ }^{\#} P<0.05$ vs. WT; ${ }^{*} P<0.05$ vs. $\mathrm{Uox}^{-1-}-1$, one-way ANOVA.

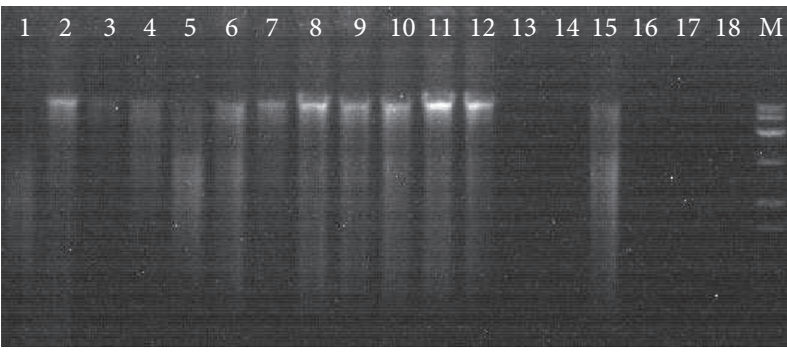

(a)

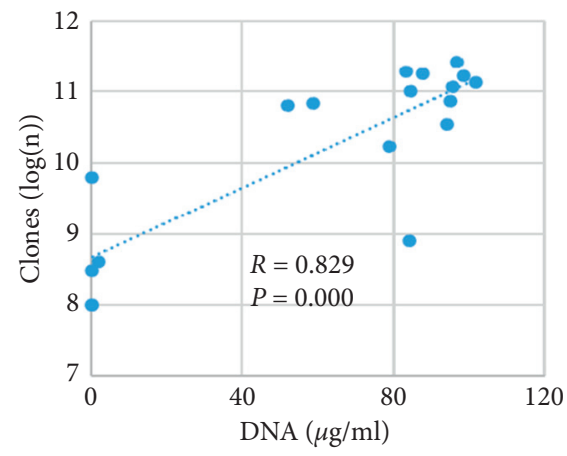

(c)

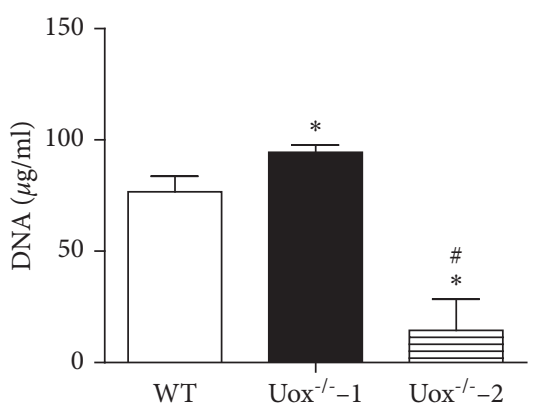

(b)

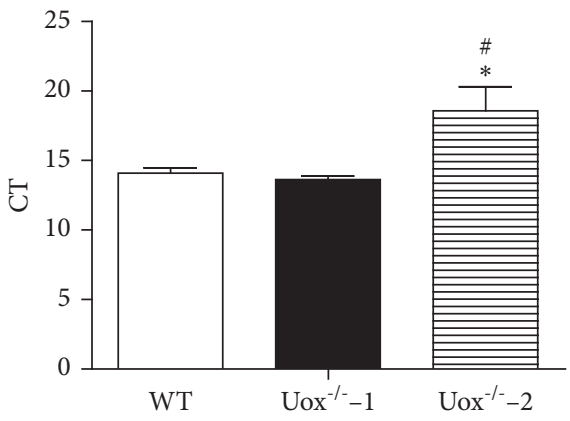

(d)

FIgure 5: Continued. 


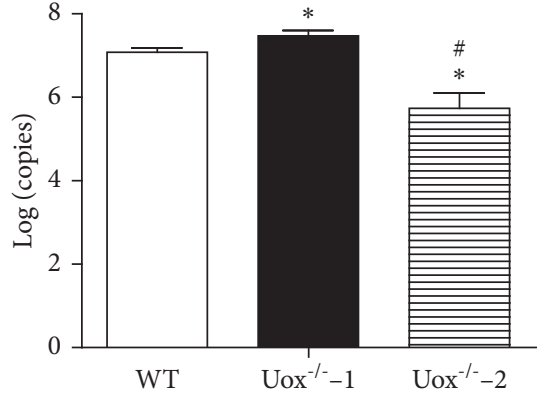

(e)

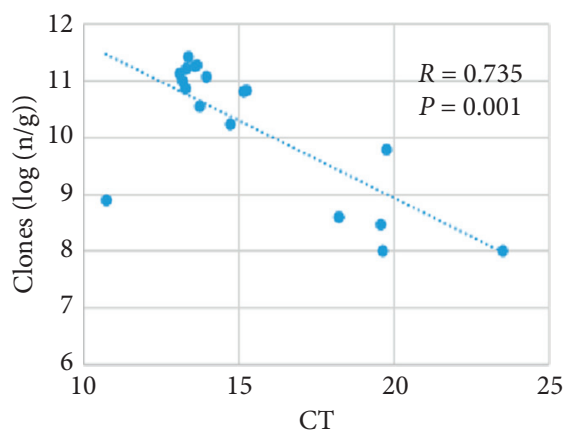

(f)

FIgURE 5: Bacterial abundance in Uox $^{-/-}$rat stool measured by DNA (mean $+\mathrm{SD}, n=6$ ). (a) Total DNA extracted from rat stool (nos. 1-6 were from WT rat stool, nos. 7-12 were from normal Uox $^{-/-}$rats', nos. 13-18 were from Uox ${ }^{-1-}$ rats treated with the combination of antibiotics, and " $\mathrm{M}$ " was the marker with the brightest band of 5,000 bp); (b) DNA content in samples (mean + SD, $n=6)$; (c) the correlation between the amount of bacterial DNA and the quantity of living bacteria $(n=18), P=0.000$, Pearson's correlation (two-tailed); (d) cycle threshold (CT) values of $16 \mathrm{~S}$ rDNA in samples (mean $+\mathrm{SD}, n=6)$; (e) copies of $16 \mathrm{~S}$ rDAN in samples (mean $+\mathrm{SD}, n=6)$; (f) the correlation between CT values and the quantity of living bacteria $(n=18), P=0.001$, Pearson's correlation (two-tailed). WT, stool from the wild-type rats; $\operatorname{Uox}^{-1-}-1$, stool from the normal Uox ${ }^{-1-}$ rats; $\operatorname{Uox}^{-1-}-2$, stool from the Uox ${ }^{-/-}$rats treated with ampicillin $(90 \mathrm{mg} / \mathrm{kg})$ and ciprofloxacin $(150 \mathrm{mg} / \mathrm{kg})$ for 5 days. ${ }^{\#} P<0.05$ vs. WT; ${ }^{*} P<0.05$ vs. Uox ${ }^{-/-}-1$, one-way ANOVA.
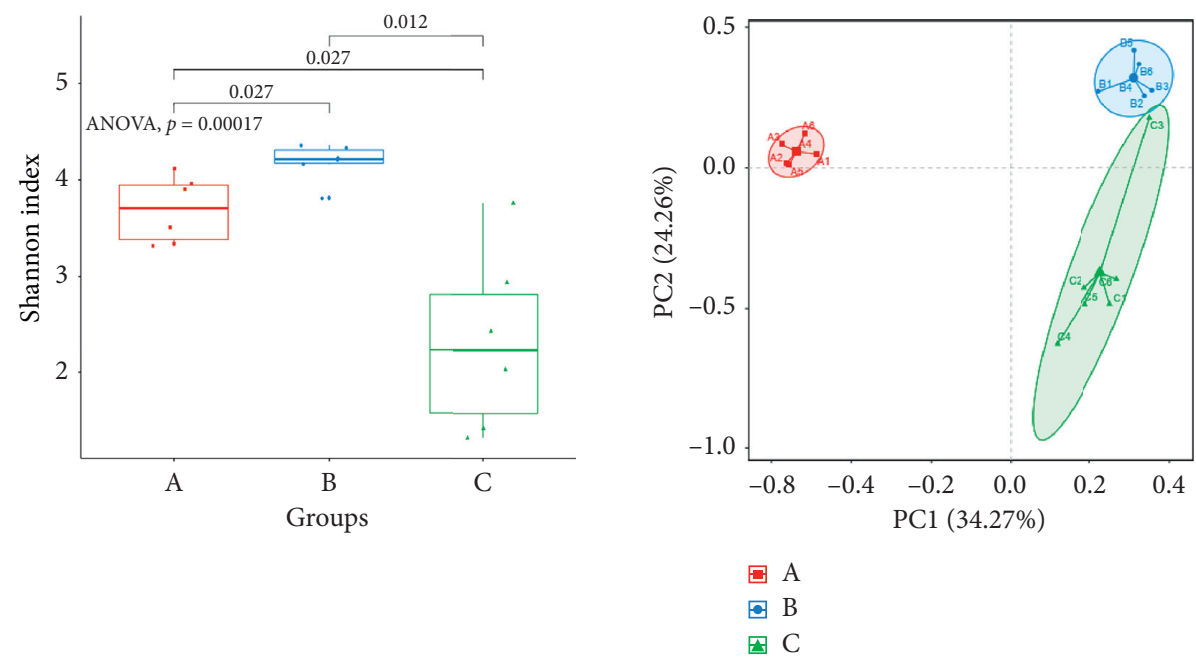

(a)

(b)

Figure 6: Continued. 


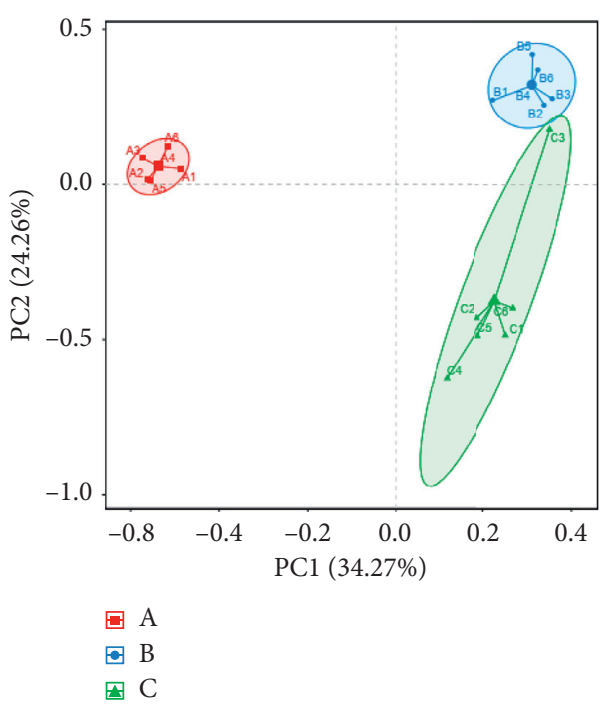

(c)

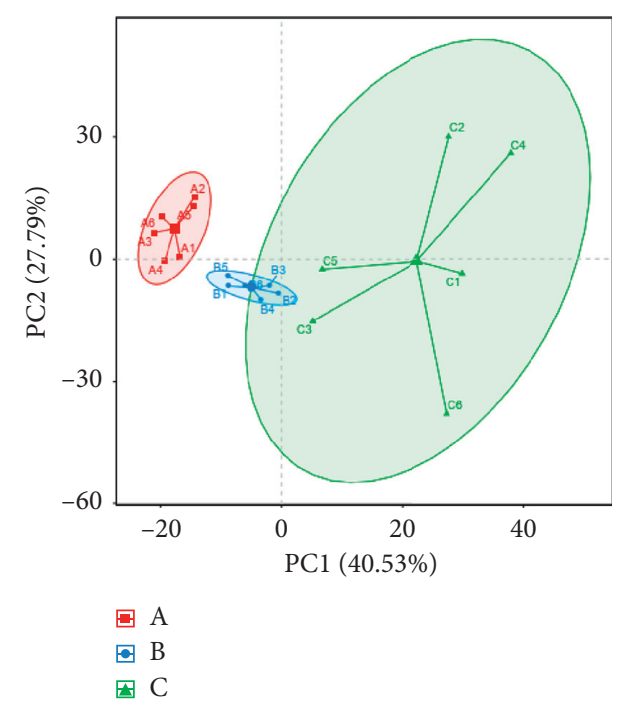

(d)

Figure 6: The floral diversity of bacteria in the $\operatorname{Uox}^{-/-}$rat stool $(n=6)$. (a) Alpha diversity (Shannon index) $(n=6)$; ${ }^{*} P<0.05$, Student's- $t$ test; (b) beta-diversity based on the PCA at the OTU level; (c) beta-diversity at the genus level; (d) beta-diversity at the species level. Group A, wild-type rat stool; group B, normal $\mathrm{Uox}^{-/-}$rats' stool; group C, stool from the $\mathrm{Uox}^{-1-}$ rats treated with antibiotics (ampicillin, $90 \mathrm{mg} / \mathrm{kg}$, and ciprofloxacin, $150 \mathrm{mg} / \mathrm{kg}$ ) for 5 days.

$\mathrm{L}$

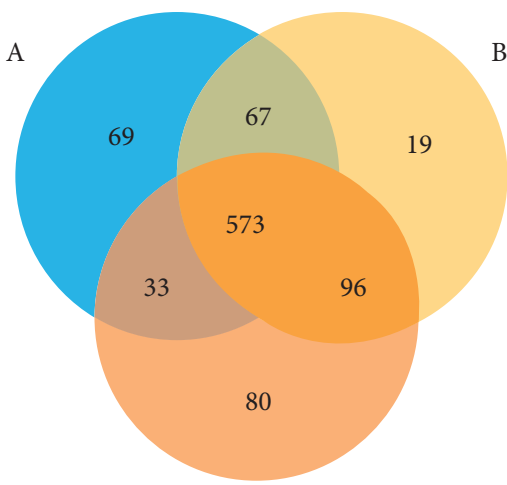

C

(a)

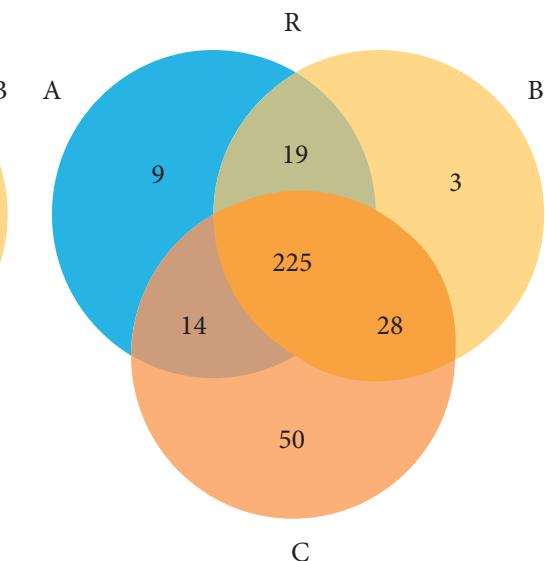

(b)

Figure 7: Venn distribution of the bacteria in the $\mathrm{Uox}^{-1-}$ rat stool at OTU (a) and genus (b) levels $(n=6)$. Group A (blue), wild-type rat stool; group B (yellow), Uox $^{-1-}$ rat stool; group C (orange), stool from Uox $^{-1-}$ rats treated with antibiotics (ampicillin, $90 \mathrm{mg} / \mathrm{kg}$, and ciprofloxacin, $150 \mathrm{mg} / \mathrm{kg}$ ) for 5 days.

ciprofloxacin. Since most bacteria can degrade uric acid, it is expected that dramatic killing or inhibition of these bacteria would elevate the SUA levels in Uox ${ }^{-/-}$rats. However, the expected results were not obtained in the present study, suggesting that the aboriginal bacteria might not be the main factor affecting the SUA level [2]. In contrast, the combination of antibiotics lowered the Uox ${ }^{-/-}$rat SUA level, which could explained by the mild antibiotic diarrhea [15] because the rats treated with the combination of antibiotics excreted more stool than the normal Uox $^{-/-}$rats. The mild diarrhea was recovered if the antibiotics were withdrawn for 3 or more days. Interestingly, ampicillin or ciprofloxacin alone did not cause diarrhea in this study.
Ampicillin can lower SUA in humans because, like probenecid, the drug can competitively inhibit uric acid reabsorption in the kidney [16]. However, the effect was not observed in the present study. Indeed, human urate transporter SLC22A11 (OAT4) is the transporter associated with uric acid reclamation and can be inhibited by probenecid and penicillin [17]. However, the transporter is not expressed in the rat' kidney, and probenecid showed a poor effect on the lowering SUA levels in rats [18]. As a quinolone, ciprofloxacin is a substrate of ABCG2 [19], an important transporter facilitating uric acid excretion $[20,21]$. ABCG2 is a transporter participating in urate excretion. By hydrolyzing ATP, ABCG2 can actively 
(Phylum)

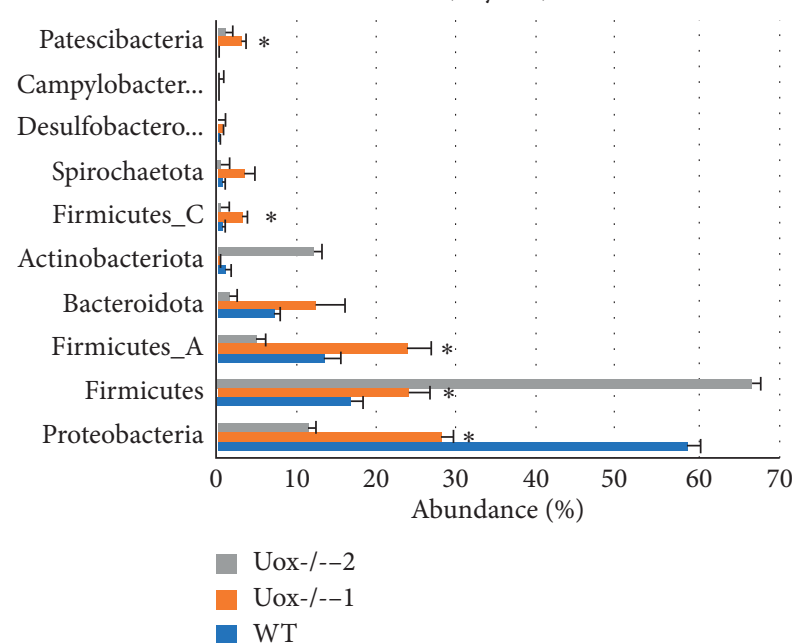

(a)

(Order)

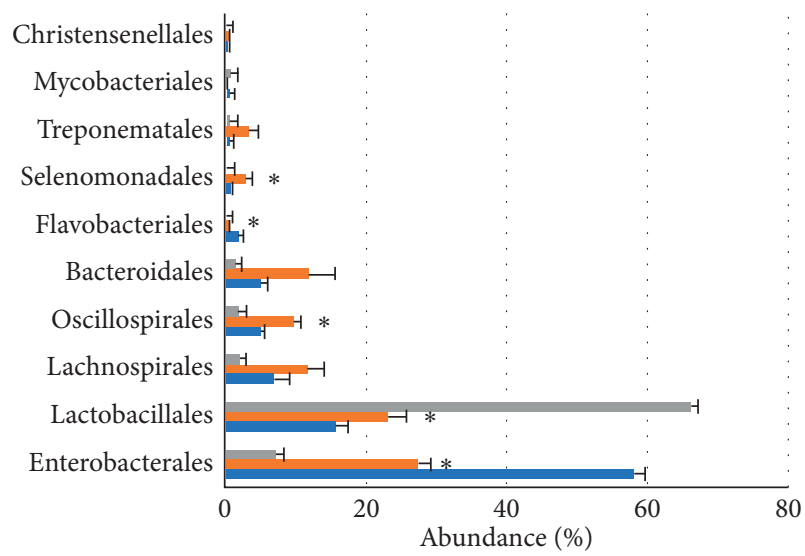

Uox-/--2

Uox-/--1

- WT

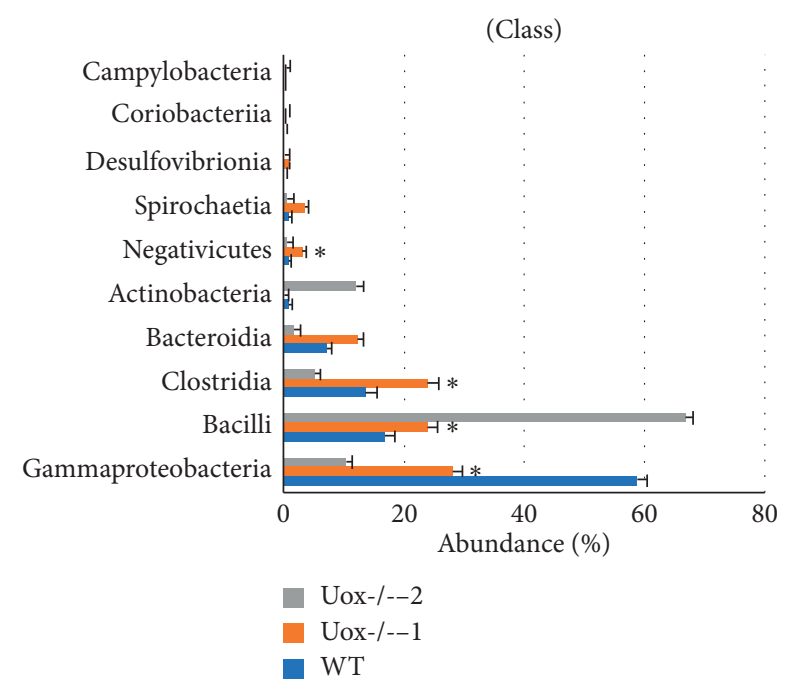

(b)

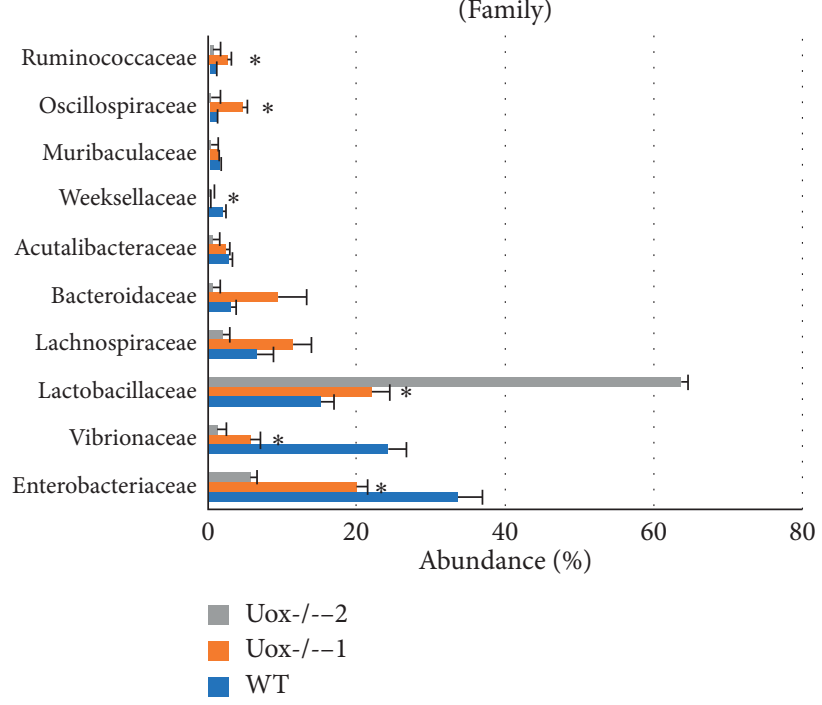

(d)

Figure 8: Continued. 


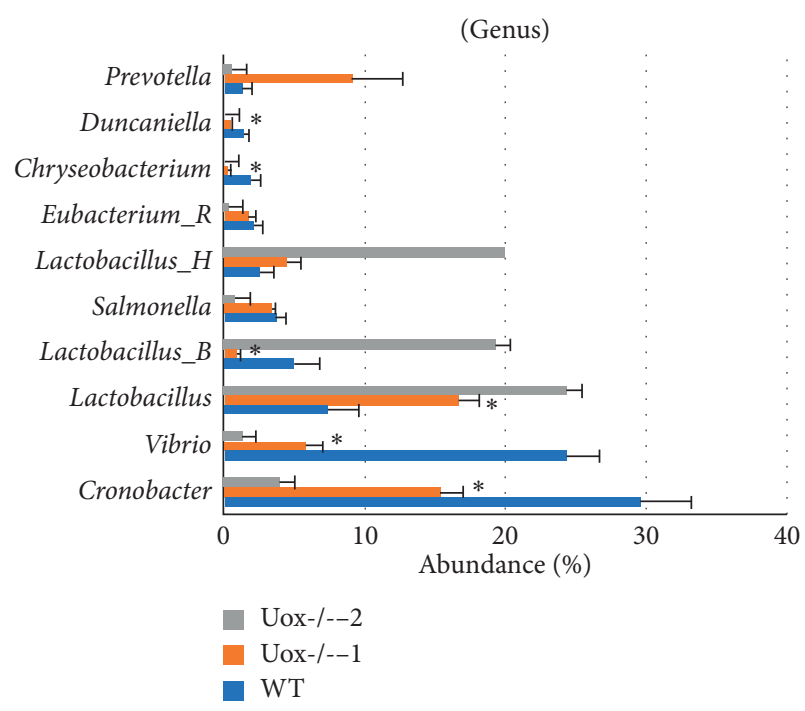

(e)

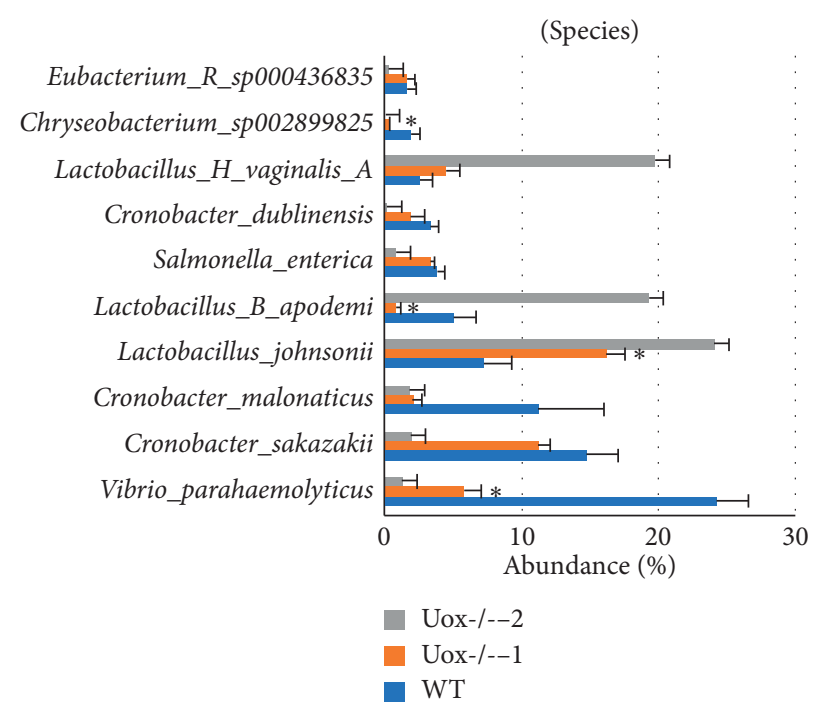

(f)

FIgURE 8: Bacterial abundance of the wild-type (WT) rats and Uox ${ }^{-/-}$rats' stool at phylum (a), class (b), order (c), family (d), genus (e), and species (f) levels (mean \pm SE, $n=6$ ). The top 10 bacteria in the WT rats' stool were listed in order, and those in the normal Uox ${ }^{-/-}$rats $\left(\mathrm{Uox}^{-/-}\right.$ $-1)$ and the $\operatorname{Uox}^{-/-}$rats treated with the combination of antibiotics (Uox ${ }^{-1-}-2$, ampicillin $(90 \mathrm{mg} / \mathrm{kg})$ and ciprofloxacin $(150 \mathrm{mg} / \mathrm{kg})$ for 5 days) were also listed. The top 10 in the Uox $^{-1-}-2$ group were listed without analysis because more than $99 \%$ of bacteria were inhibited or killed by antibiotics. (a) The top 10 bacteria at the phylum level covered $99.75 \%$ of all bacteria in the WT rats and $99.65 \%$ in the normal Uox ${ }^{-/-}$ rats; (b) the top 10 at the class level covered $99.50 \%$ in the WT rats and $96.30 \%$ in the normal Uox ${ }^{-1-}$ rats; (c) the top 10 at the order level covered $96.29 \%$ in the WT rats and $91.61 \%$ in the normal Uox $^{-1-}$ rats; (d) the top 10 at the family level covered $92.21 \%$ in the WT rats and $80.91 \%$ in the normal Uox $^{-/-}$rats; (e) the top 10 at the genus level covered $80.14 \%$ in the WT rats and $58.72 \%$ in the normal Uox ${ }^{-/-}$rats; and (e) the top 10 at the species level covered $76.51 \%$ in the WT rats and $48.44 \%$ in the normal Uox $^{-/-}$rats. $^{*} P<0.05$ vs. WT, Student's $t$-test.

TABLE 1: The top 10 genera in rat stool.

\begin{tabular}{|c|c|c|c|c|c|c|}
\hline \multirow{2}{*}{ No. } & \multicolumn{2}{|c|}{ WT } & \multicolumn{2}{|c|}{$\operatorname{Uox}^{-/-}-1$} & \multicolumn{2}{|c|}{$\operatorname{Uox}^{-/-}-2^{*}$} \\
\hline & Genus & Abundance (\%) & Genus & Abundance (\%) & Genus & Abundance (\%) \\
\hline 1 & Cronobacter & 29.60 & Lactobacillus & 16.72 & Lactobacillus & 24.39 \\
\hline 2 & Vibrio & 24.40 & Cronobacter & 15.44 & Lactobacillus_H & 19.91 \\
\hline 3 & Lactobacillus & 7.51 & Prevotella & 9.13 & Lactobacillus_B & 19.37 \\
\hline 4 & Lactobacillus_B & 5.08 & Vibrio & 5.85 & Rothia & 10.65 \\
\hline 5 & Salmonella & 3.82 & Lactobacillus_H & 4.55 & Cronobacter & 4.00 \\
\hline 6 & Lactobacillus_H & 2.68 & Kineothrix & 4.01 & Pseudomonas_E & 2.03 \\
\hline 7 & Eubacterium_R & 2.18 & Treponema_D & 3.52 & Vibrio & 1.33 \\
\hline 8 & Chryseobacterium & 2.01 & Salmonella & 3.43 & Enterococcus & 1.26 \\
\hline 9 & Duncaniella & 1.53 & Schwartzia & 2.96 & Streptococcus & 1.11 \\
\hline 10 & Prevotella & 1.35 & Saccharimonas & 2.93 & Saccharimonas & 1.04 \\
\hline \multicolumn{2}{|c|}{ Total (267) } & 80.20 & Total (275) & 68.50 & Total (317) & 67.55 \\
\hline
\end{tabular}

${ }^{*}$ More than $99 \%$ of bacteria in stool were inhibited or killed in the Uox $^{-1-}-2$ group treated by the combination of antibiotics. WT rats, wild-type rats; Uox ${ }^{-1-}-1$, normal Uox ${ }^{-1-}$ rats; $\operatorname{Uox}^{-1-}-2$, Uox ${ }^{-/-}$rats treated with combinatorial antibiotics (ampicillin $(90 \mathrm{mg} / \mathrm{kg}$ ) and ciprofloxacin $(150 \mathrm{mg} / \mathrm{kg})$ for $5 \mathrm{days}$ ).

pump urate to renal tubular lumen [22] or intestinal fluids [23]. ABCG2 deficiency was proved to be a key factor to increase SUA in both human [24] and mice [25]. The two substrates (ciprofloxacin and urate) could compete for the function of ABCG2 and increase the SUA level (Figure 1(d)).

Since fungi normally distributed in the rat intestinal tract have very low abundance [2], the bacteria could be the main microbe to maintain the microecological balance. Though the bacteria may play a crucial role in maintaining human health, the effect of the aboriginal bacteria on the SUA level may be negligible. Exogenous factors such as antibiotics [7], probiotics [15], and prebiotics [26] have been reported to affect SUA levels by inhibiting, supplementing, or promoting bacteria growth, but their effectiveness needs to be further proved in clinical trials. It should be noted that the chemicals and the bacteria would cause aboriginal microecological disturbance. Bacteria are tiny organisms with a high metabolic state in the gut; they synthesize purines besides degrading uric acid, and the purines are released from bacterial bodies. The released purines can be absorbed by their host and transformed into uric acid. Theoretically, uric acid could not be the favorite "food" of microorganisms if nutrients, such as proteins, 


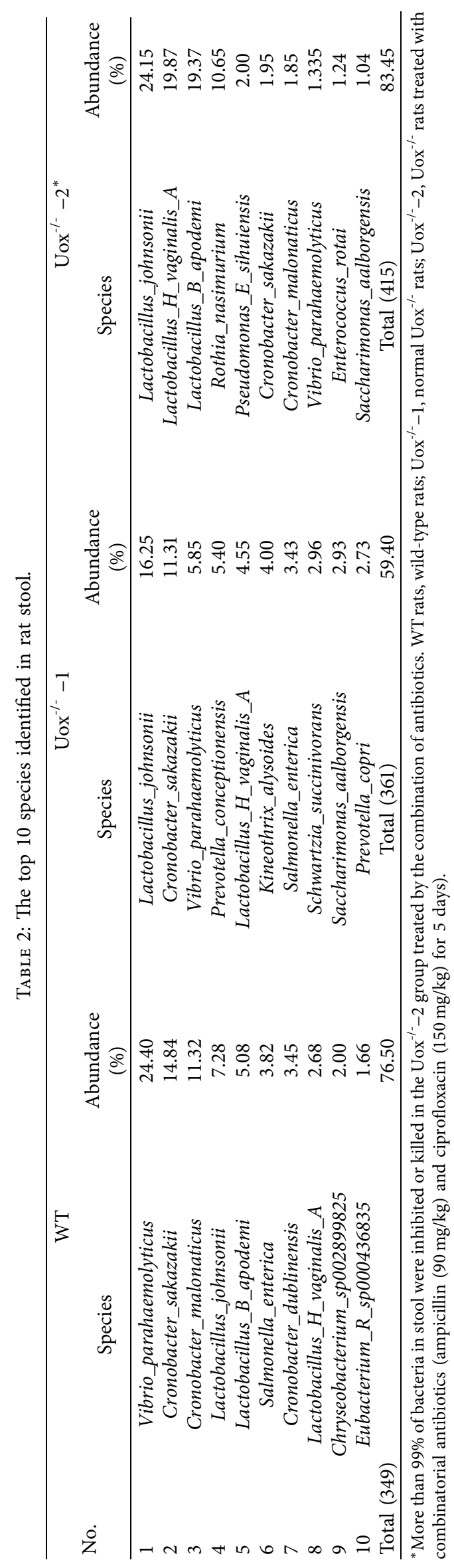


TABLE 3: Genera can generate uricase of the top 10 in WT and Uox-/--1 groups.

\begin{tabular}{|c|c|c|c|c|c|c|c|}
\hline \multirow{2}{*}{ No. } & \multirow{2}{*}{ Genus } & \multicolumn{3}{|c|}{ Rank } & \multirow{2}{*}{ Uox nucleotide } & \multirow{2}{*}{ Uricase protein } & \multirow{2}{*}{ Note } \\
\hline & & WT & $\mathrm{Uox}^{-/-}-1$ & $\operatorname{Uox}^{-1-}-2$ & & & \\
\hline 1 & Chryseobacterium & 8 & - & - & $\mathrm{N}$ & $\mathrm{N}$ & - \\
\hline 2 & Cronobacter & 1 & 2 & 5 & $\mathrm{Y}$ & $\mathrm{N}$ & - \\
\hline 3 & Duncaniella & 9 & - & & $\mathrm{N}$ & $\mathrm{N}$ & - \\
\hline 4 & Enterococcus & - & - & 8 & $\mathrm{~N}$ & $\mathrm{~N}$ & - \\
\hline 5 & Eubacterium_R & 7 & - & - & $\mathrm{N}$ & $\mathrm{N}$ & - \\
\hline 6 & Lactobacillus & 3 & 1 & 1 & $\mathrm{~N}$ & $\mathrm{Y}$ & Partial aa sequence \\
\hline 7 & Lactobacillus_B & 4 & & 3 & $\mathrm{~N}$ & $\mathrm{Y}$ & Partial aa sequence \\
\hline 8 & Lactobacillus_H & 6 & 5 & 2 & $\mathrm{~N}$ & $\mathrm{Y}$ & Partial aa sequence \\
\hline 9 & Kineothrix & & 6 & & $\mathrm{~N}$ & $\mathrm{~N}$ & - \\
\hline 10 & Prevotella & 10 & 3 & & $\mathrm{~N}$ & $\mathrm{~N}$ & - \\
\hline 11 & Pseudomonas_E & & & 6 & $\mathrm{Y}$ & $\mathrm{Y}$ & - \\
\hline 12 & Rothia & & & 4 & $\mathrm{~N}$ & $\mathrm{Y}$ & - \\
\hline 13 & Saccharimonas & & 10 & 10 & $\mathrm{~N}$ & $\mathrm{~N}$ & - \\
\hline 14 & Salmonella & 5 & 8 & - & $\mathrm{Y}$ & $\mathrm{N}$ & - \\
\hline 15 & Schwartzia & & 9 & - & $\mathrm{N}$ & $\mathrm{N}$ & - \\
\hline 16 & Streptococcus & & & 9 & $\mathrm{~N}$ & $\mathrm{Y}$ & - \\
\hline 17 & Treponema_D & & 7 & & $\mathrm{~N}$ & $\mathrm{~N}$ & - \\
\hline 18 & Vibrio & & 4 & 7 & $\mathrm{Y}$ & $\mathrm{Y}$ & - \\
\hline
\end{tabular}

The top 10 genera cited from Table 1. WT, wild-type rats; $\mathrm{Uox}^{-1-}-1$, normal $\mathrm{Uox}^{-1--}$ rats; $\mathrm{Uox}^{-1-}-2, \mathrm{Uox}^{-/-}-2$ treated with combinatorial antibiotics (ampicillin, $90 \mathrm{mg} / \mathrm{kg}$, and ciprofloxacin, $150 \mathrm{mg} / \mathrm{kg}$, for 5 days), and more than $99 \%$ bacteria in the group were inhibited or killed. Note: N, the nucleotide of Uox and uricase amino acid (aa) sequence cannot be presently found in the database (https://www.ncbi.nlm.nih.gov/nucleotide/for Uox and https://www.ncbi.nlm. nih.gov/protein/for uricase); $\mathrm{Y}$, the nucleotide of Uox or uricase amino acid sequence can be found in the database.

carbohydrates, and fats are available in the gut, unless the microorganism was an engineered one. It is difficult for us to expect that the aboriginal bacteria can degrade uric acid more powerfully than they synthesize purines, except for the engineered bacteria [8]. However, the engineered microorganisms would theoretically cause an unexpected microecological disturbance.

It should be noted that the bacteria in the wild-type rats' gut were different from those reported recently [7]. This could be due to the regional difference. The experiment of the report [7] was performed in north China, and the present experiment was conducted in southwest China. Nevertheless, similar to the present study, the report [7] stated that the combination of antibiotics (ampicillin, neomycin, and metronidazole) decreased the SUA level, with a weak but a significant effect in "hyperuricemia" rats. Undoubtedly, the results also agreed with the present study in which the aboriginal gut bacteria were not the main factors to lower the SUA level, though most of them expressed uricase to degrade uric acid.

\section{Conclusions}

The bacterial flora in the $\mathrm{Uox}^{-/-}$rat gut was altered, and the gut aboriginal bacteria are not the main factor affecting the SUA level.

\section{Data Availability}

The data used to support the findings of this study are included within the article and Supplementary Materials.

\section{Conflicts of Interest}

The authors declare that they have no conflicts of interest.

\section{Authors' Contributions}

Nan Fan and Lvyu Li contributed equally to this work.

\section{Acknowledgments}

The work was financially supported by the National Natural Science Foundation of China (81860162).

\section{Supplementary Materials}

The supplement.docx is the supplementary dataset in table format supporting Figures 1-8. (Supplementary Materials)

\section{References}

[1] B. Engel, J. Just, M. Bleckwenn, and K. Weckbecker, "Treatment options for gout," Deutsches Arzteblatt International, vol. 114, no. 13, pp. 215-222, 2017.

[2] Y. Yun, H. Yin, Z. Gao et al., "Intestinal tract is an important organ for lowering serum uric acid in rats," PLoS One, vol. 12, no. 12, Article ID e0190194, 2017.

[3] P. Szczurek, N. Mosiichuk, J. Wolinski et al., "Oral uricase eliminates blood uric acid in the hyperuricemic pig model," PLoS One, vol. 12, no. 6, Article ID e0179195, 2017.

[4] M. Zhao, L. Li-Hui, L. Jing et al., "Montmorillonite adsorbs uric acid and increases the excretion of uric acid from the intestinal tract in mice," Journal of Pharmacy Pharmacology, vol. 61, pp. 1499-1504, 2009.

[5] X. Dong, N. Fan, Y. Yun et al., "Paidu yangyan capsules lowered serum uric acid in uricase-deficient rats," Journal of Yunnan University of Traditional Chinese Medicine, vol. 40, no. 3, pp. 1-4, 2020.

[6] R. M. Hafez, T. M. Abdel-Rahman, and R. M. Naguib, "Uric acid in plants and microorganisms: biological applications 
and genetics - a review," Journal of Advanced Research, vol. 8, no. 5, pp. 475-486, 2017.

[7] X. Liu, Q. Lv, H. Ren et al., "The altered gut microbiota of high-purine-induced hyperuricemia rats and its correlation with hyperuricemia,” PeerJ, vol. 8, Article ID e8664, 2020.

[8] L. Cai, Q. Li, Y. Deng et al., "Construction and expression of recombinant uricase-expressing genetically engineered bacteria and its application in rat model of hyperuricemia," International Journal of Molecular Medicine, vol. 45, no. 5, pp. 1488-1500, 2020.

[9] Y. Yu, N. Zhang, X. Dong et al., "Uricase-deficient rat is generated with CRISPR/Cas9 technique," PeerJ, vol. 8, no. 11, Article ID e8971, 2020.

[10] X. Wu, M. Wakamiya, S. Vaishnav et al., "Hyperuricemia and urate nephropathy in urate oxidase-deficient mice," Proceedings of the National Academy of Sciences, vol. 91, no. 2, pp. 742-746, 1994.

[11] J. Lu, X. Hou, X. Yuan et al., "Knockout of the urate oxidase gene provides a stable mouse model of hyperuricemia associated with metabolic disorders," Kidney International, vol. 93, no. 1, pp. 69-80, 2018.

[12] T. Watanabe, N. H. Tomioka, S. Watanabe et al., "False in vitro and in vivo elevations of uric acid levels in mouse blood," Nucleosides Nucleotides Nucleic Acids, vol. 33, no. 4, pp. 192-198, 2014.

[13] D. H. Yang, Y. Y. Zhang, P. C. Du et al., "Rapid identification of bacterial species associated with bronchiectasis via metagenomic approach," Biomedical and Environmental Sciences: BES, vol. 27, no. 11, pp. 898-901, 2014.

[14] D. Timofte, M. D. Tanasescu, D. G. Balan et al., "Management of acute intradialytic cardiovascular complications: updated overview (Review)," Experimental and Therapeutic Medicine, vol. 21 , no. 3, p. $282,2021$.

[15] A. Guentsch, "Antibiotics against periodontal biofilms," Oral Biofilms, vol. 29, pp. 119-132, 2021.

[16] D. K. Sommers and H. S. Schoeman, "Drug interactions with urate excretion in man," European Journal of Clinical Pharmacology, vol. 32, no. 5, pp. 499-502, 1987.

[17] Y. Hagos, D. Stein, B. Ugele, G. Burckhardt, and A. Bahn, "Human renal organic anion transporter 4 operates as an asymmetric urate transporter," Journal of the American Society of Nephrology, vol. 18, no. 2, pp. 430-439, 2007.

[18] T. Taniguchi, N. Ashizawa, K. Matsumoto, T. Iwanaga, and K. Saitoh, "Uricosuric agents decrease the plasma urate level in rats by concomitant treatment with topiroxostat, a novel xanthine oxidoreductase inhibitor," Journal of Pharmacy and Pharmacology, vol. 68, no. 1, pp. 76-83, 2016.

[19] I. S. Haslam, J. A. Wright, D. A. O'Reilly, D. J. Sherlock, T. Coleman, and N. L. Simmons, "Intestinal ciprofloxacin efflux: the role of breast cancer resistance protein (ABCG2)," Drug Metabolism and Disposition, vol. 39, no. 12, pp. 2321-2328, 2011.

[20] C. Morimoto, Y. Tamura, S. Asakawa et al., "ABCG2 expression and uric acid metabolism of the intestine in hyperuricemia model rat," Nucleosides, Nucleotides \& Nucleic Acids, vol. 39, no. 5, pp. 744-759, 2020.

[21] A. Hosomi, T. Nakanishi, T. Fujita et al., "Extra-renal elimination of uric acid via intestinal efflux transporter BCRP/ ABCG2," PLoS One, vol. 7, no. 2, Article ID e30456, 2012.

[22] O. M. Woodward, A. Kottgen, J. Coresh, E. Boerwinkle, W. B. Guggino, and M. Kottgen, "Identification of a urate transporter, ABCG2, with a common functional polymorphism causing gout," Proceedings of the National Academy of Sciences, vol. 106, no. 25, pp. 10338-10342, 2009.
[23] T. Takada, K. Ichida, H. Matsuo et al., "ABCG2 dysfunction increases serum uric acid by decreased intestinal urate excretion," Nucleosides Nucleotides Nucleic Acids, vol. 33, no. 4-6, pp. 275-281, 2014.

[24] Y. Toyoda, K. Pavelcova, J. Bohata et al., "Identification of two dysfunctional variants in the ABCG2 urate transporter associated with pediatric-onset of familial hyperuricemia and early-onset gout," International Journal of Molecular Sciences, vol. 22, no. 4, 2021.

[25] H. Matsuo, A. Nakayama, M. Sakiyama et al., "ABCG2 dysfunction causes hyperuricemia due to both renal urate underexcretion and renal urate overload," Scientific Report, vol. 4, p. 3755, 2014.

[26] J. Wang, Y. Chen, H. Zhong et al., "The gut microbiota as a target to control hyperuricemia pathogenesis: potential mechanisms and therapeutic strategies," Critical Reviews in Food Science and Nutrition, vol. 22, pp. 1-11, 2021. 